Original Paper

\title{
Hydrothermal Treatment of Cellulose as a Pretreatment for Ethanol Fermentation: Cellulose Hydrolysis Experiments
}

\author{
Takuya YoshidA ${ }^{* 1}$, Hiroshi NONAKA ${ }^{* 2}$, and Yukihiko MATSUMURA $* 1 * 3$ \\ (Received October 20, 2004)
}

\begin{abstract}
Hydrothermal treatment can be applied to pretreatment of ethanol fermentation process. What is important in the pretreatment step is that lignocellulosic material be effectively hydrolyzed to smaller saccharides and not be further converted to other substances. In this study we developed reaction kinetics of cellulose hydrolysis to glucose for evaluation of hydrothermal treatment condition.
\end{abstract}

\section{Key Words}

Ethanol, Glucose, Cellulose, Hydrolysis, Hydrothermal pretreatment

\section{Introduction}

Biomass is recognized as a carbon neutral energy source. Therefore a great deal of effort has been made to utilize it effectively. Ethanol fermentation is one of the ways to utilize lignocellulosic biomass. The process is mainly divided into two processes, one is producing sugars by hydrolysis of raw materials and the other is subsequent fermentation from sugars to ethanol. However the cost of ethanol production from lignocellulosic materials is relatively high based on current technologies, and the main challenges are the low yield and high cost of the hydrolysis process ${ }^{1}$. Hydrolysis (saccharification) is usually carried out by cellulase enzymes after some kinds of pretreatments. And this pretreatment is a key factor of effective conversion to sugars in enzymatic hydrolysis.

There are many kinds of pretreatment such as pyrolysis, steam explosion, hydrothermal treatment, acid or alkaline hydrolysis and so on. The important things for pretreatments are to reduce cellulose crystallinity, to improve the formation of sugars, and to avoid the degradation of carbohydrate and the formation of byproducts inhibitory to the subsequent processes simultaneously. For these

* 1 Department of Mechanical System Engineering, Hiroshima University

1-4-1 Kagamiyama, Higashi-hiroshimashi, Hiroshima 739-8527, Japan

* 2 Microbiology Research Group, RITE 9-2, Kizugawa-dai, Kizu-Cho, Soraku-Gun, Kyoto 619-0292. Japan

* 3 Corresponding author, matumura@mec.hiroshima-u.ac.jp reasons, many investigations of pretreatment were carried out $^{2) \sim 5}$.

We can estimate better condition of pretreatment by analyzing it from the viewpoint of reaction engineering. There are some investigations about hydrothermal reaction of cellulose $^{6)}$ and cellobiose ${ }^{7)}$ presenting reaction mechanism and reaction rate equations. Cellulose is the most important substance in lignocellulosic material for ethanol fermentation process.

In this study, hydrothermal reactions of cellulose and glucose have been investigated as a pretreatment for ethanol fermentation from the viewpoint of reaction engineering. The objective of this study is to build a kinetic model of cellulose hydrolysis to glucose in hydrothermal environment.

\section{Experimental}

Fig. 1 shows the autoclave employed in this experiments and its inner volume is $90 \mathrm{~mL}$. Cellulose (Sigmacell type50, Sigma) or D-glucose (Sigma-Aldrich) was used as a reactant. In the case of cellulose experiments, $10 \mathrm{~g}$ of cellulose was loaded in the vessel with $60 \mathrm{~g}$ of ion-exchanged water. And when we conducted glucose decomposition experiment, $0.1 \mathrm{wt} \%$ glucose solution was used and total of $60 \mathrm{~g}$ solution was loaded into the vessel. The autoclave was heated up by the embedded heaters. When the temperature reached to the target value, the heaters were turned off and the reactor was cooled by air fan. The changes of 


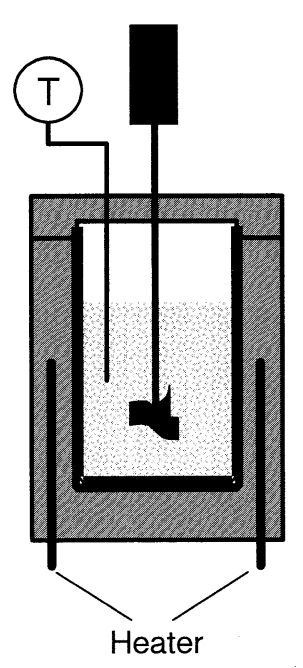

Fig. 1 Autoclave reactor

temperature of the reactor are presented in Fig. 2. Five different target temperatures $\left(150,175,200,225,250{ }^{\circ} \mathrm{C}\right)$ at heater output of $3000 \mathrm{~W}$ and different heater output (1100, $500 \mathrm{~W})$ at $225^{\circ} \mathrm{C}$ are employed. When the reactor temperature came down to $60{ }^{\circ} \mathrm{C}$, the autoclave was opened and the products inside were recovered.

Fig. 3 shows the apparatus used in flow reactor experiments. The reactor consisted of tubing made of 316 stainless with inner diameter of $1 \mathrm{~mm}$ and length of $200 \mathrm{~mm}$.

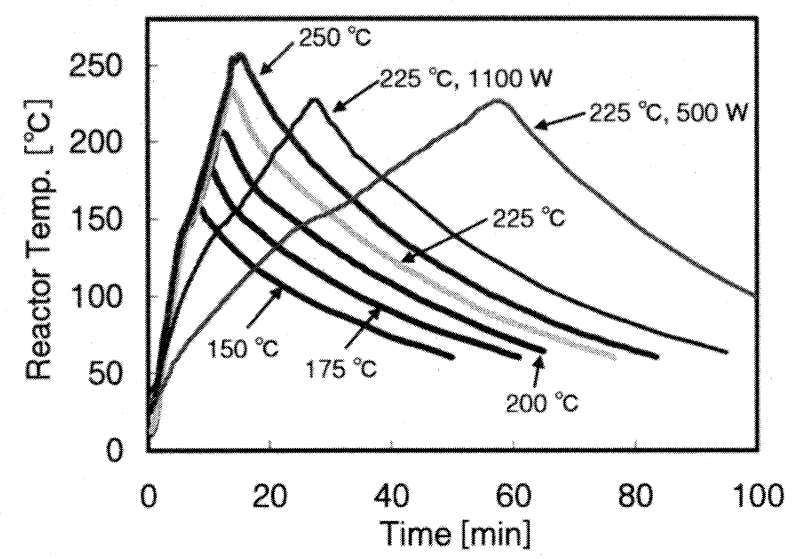

Fig. 2 Change in temperature inside the reactor with time



Fig. 3 Flow reactor for measurement of glucose decomposition rate
The $1.8 \mathrm{wt} \%$ glucose solution was fed into the reactor by an HPLC pump. To keep the solution temperature low before the reactor, heat exchanger was set in front of the reactor. And to heat the solution rapidly, hot water, which is heated to 30 - $50 \mathrm{~K}$ higher (its temperature depended on the reaction temperature) than the reactor temperature, was also fed into the reactor. The residence time in reactor was controlled by changing the reactant flow rate (4.3 $16.4 \mathrm{~g} / \mathrm{min}$ for $400{ }^{\circ} \mathrm{C}, 4.0-18.0 \mathrm{~g} / \mathrm{min}$ for $350{ }^{\circ} \mathrm{C}, 2.7-12.3 \mathrm{~g} /$ min for $300{ }^{\circ} \mathrm{C}, 1.4-12.0 \mathrm{~g} / \mathrm{min}$ for $250{ }^{\circ} \mathrm{C}$ ) so that it ranged $0.13-0.52 \mathrm{~s}$ for $400{ }^{\circ} \mathrm{C}, 0.46-4.9 \mathrm{~s}$ for $350{ }^{\circ} \mathrm{C}, 0.80-3.8 \mathrm{~s}$ for $300{ }^{\circ} \mathrm{C}, 0.91-8.0 \mathrm{~s}$ for $250{ }^{\circ} \mathrm{C}$. At the exit of the reactor, cool water was fed and heat exchanger was set so that the products were cooled immediately. The products were recovered after the backpressure regulator.

In each experiment, the liquid product was analyzed by HPLC with a SUGAR KS-802 (Shodex) column operated at $50{ }^{\circ} \mathrm{C}$ with a $0.5 \mathrm{~mL} / \mathrm{min}$ flow of water as an eluate. The detector was a refractive index (RI) (Shimadzu, RID-10A) detector.

\section{Results and discussions}

Fig. 4 shows the products of cellulose decomposition experiments. The higher the operating temperature is, the darker the color of the products is. Fig. 5 shows the HPLC chart of cellulose experiment products at $225{ }^{\circ} \mathrm{C}$. Main products were oligomers (a) including cellobiose (b), glucose (c)

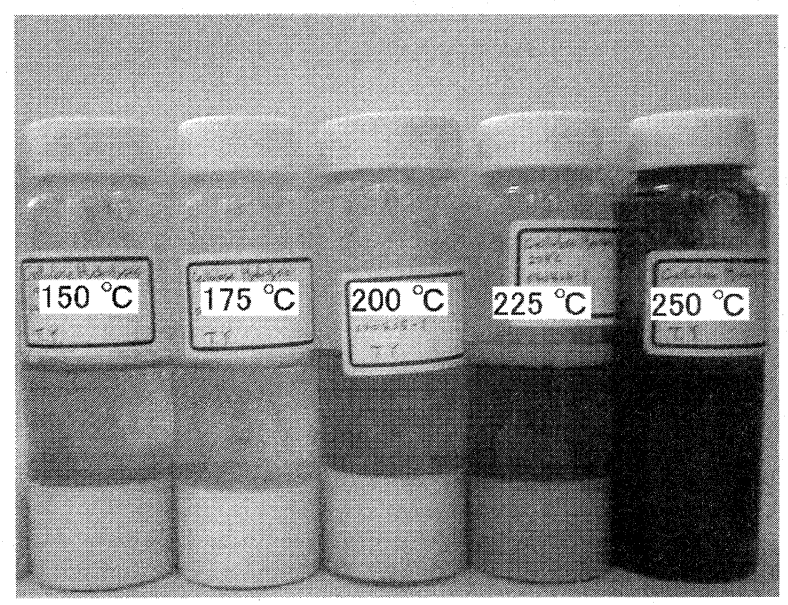

Fig. 4 Outlook of the products for hydrothermal treatment of cellulose

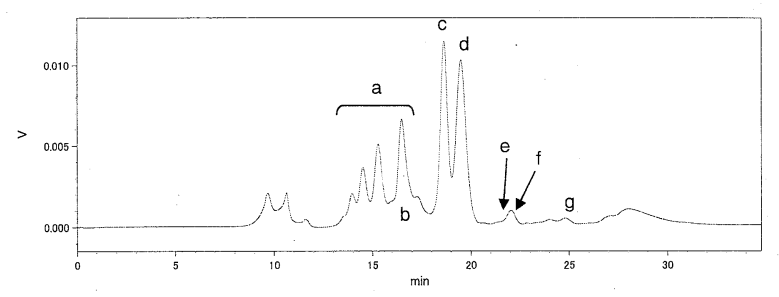

Fig. 5 HPLC-RI chromatogram of cellulose experiment with autoclave at $225{ }^{\circ} \mathrm{C}$ 
and fructose (d). We also detected grycelaldehyde (e), erythrose (f), 1,6-anhydroglucose (g), which are glucose decomposition products. At this temperature, the selectivity of fructose tends to be rather high compared with similar experiments but at higher temperature conducted by Hayashi et $\mathrm{al}^{8}$. It is because hydrolysis rate of cellulose becomes higher when temperature goes up while epimerization rate of glucose to fructose doesn' $t$ become so much higher. Table 1 presents the glucose yield on each condition. The yields indicate that higher operating temperature causes higher glucose yield. It is known that cellulose and hemicellulose are hydrolyzed and form oligomers and monosaccharide. The most important thing in hydrolysis of lignocellulosic resources as a pretreatment for ethanol fermentation process is to decompose polysaccharides effectively and simultaneously suppress formation of undesirable products such as furfural and 5hydroxymethylfurfural which are degradation products of monosaccharide ${ }^{9)}$.

To confirm how much glucose will decompose in hydrothermal treatment, we conducted glucose decomposition experiments. Tables 2 and 3 show the results of glucose conversion in autoclave reactor at several different temperatures and different heater outputs. The glucose conversion increased with increasing the setting temperature. And the difference of heater output is related with difference of reaction time. And the results show that long reaction time results in high glucose conversion.

We also conducted glucose decomposition experiments employing flow reactor at temperatures of 523, 573, 623, and $673 \mathrm{~K}$ and pressure of $25 \mathrm{MPa}$ to acquire a rate equation of glucose reaction. Fig. 6 shows typical HPLC chart of glucose decomposition products in this experiments. We detected fructose (d), erythrose (f) and 1,6-anhydroglucose (g). Fig. 7 gives the experimental results of glucose decomposition in terms of $-\ln (1-\mathrm{X})$ versus time. Fig. 8 pre-

Table 1 Effect if reaction temperature on glucose yield for hydrothermal treatment of cellulose

\begin{tabular}{cccccc}
\hline Temp $\left[{ }^{\circ} \mathrm{C}\right]$ & 150 & 175 & 200 & 225 & 250 \\
\hline Glucose yield $[-]$ & 0 & 0 & 0 & 0.006 & 0.222 \\
\hline
\end{tabular}

Table 2 Effect of reaction temperature on glucose decomposition for hydrothermal treatment of glucose

\begin{tabular}{ccccc}
\hline Temp [ $\left.{ }^{\circ} \mathrm{C}\right]$ & 175 & 200 & 225 & 250 \\
\hline Glucose conversion[-] & 0.234 & 0.324 & 0.654 & 0.943 \\
\hline
\end{tabular}

Table 3 Effect of heater output on glucose yield for hydrothermal treatment of cellulose

\begin{tabular}{cccc}
\hline Heater output [W] & 500 & 1100 & 3000 \\
\hline Glucose conversion [-] & 0.77 & 0.713 & 0.654 \\
\hline
\end{tabular}



Fig. 6 HPLC-RI chromatogram of glucose experiment with flow reactor at $250{ }^{\circ} \mathrm{C}, 8 \mathrm{~s}$

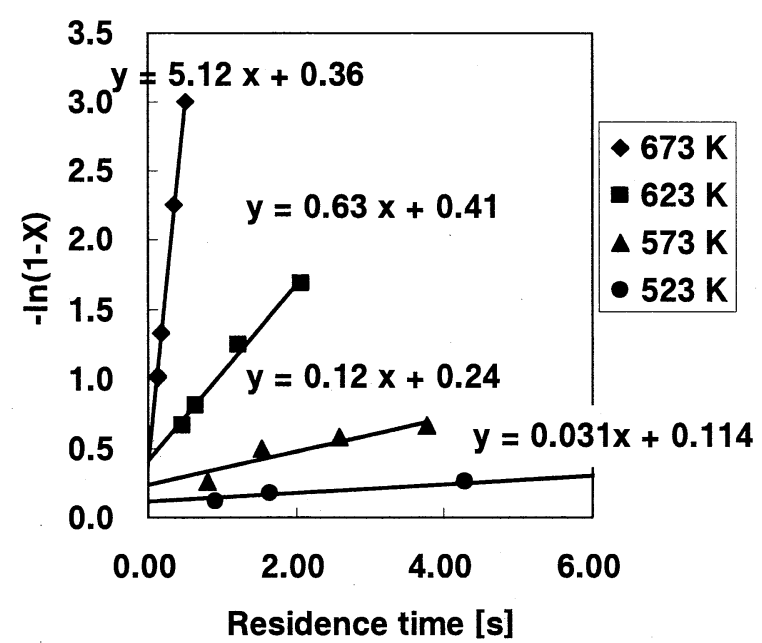

Fig. 7 Effect of temperature on glucose decomposition in hot compressed water

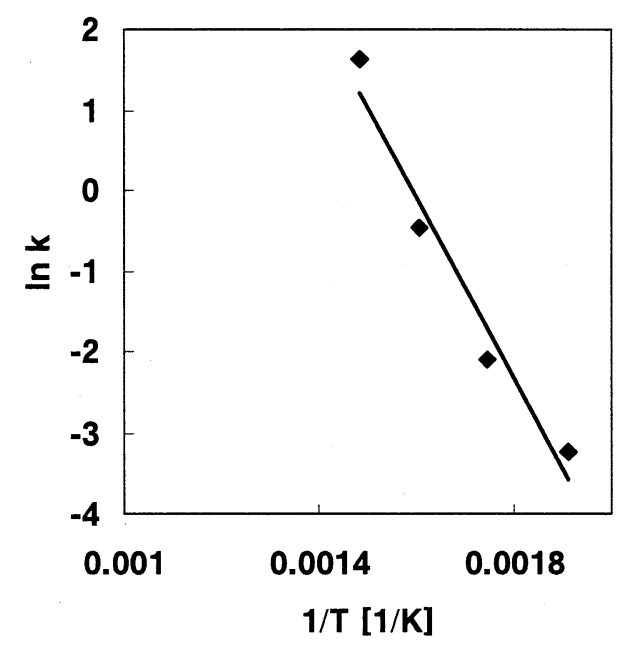

Fig. 8 Arrhenius plot for glucose decomposition in hot compressed water

sents the Arrhenius plot of this reaction. From these results, we got an activation energy of $93.5 \mathrm{~kJ} / \mathrm{mol}$ and preexponential factor of $6.13 \times 10^{7} \mathrm{~s}^{-1}$. By integrating the rate equation as Eq. (1), we calculated the glucose conversion of autoclave experiments, which are shown in Fig. 9.

$$
\mathrm{X}=\int\left[6.13 \times 10^{7} \mathrm{~s}^{-1}\right] \exp (-93.5 \mathrm{~kJ} / \mathrm{mol} / \mathrm{R} \mathrm{T}(\mathrm{t}))(1-\mathrm{X}) \mathrm{dt}(1)
$$

$\mathrm{T}(\mathrm{t})$ : temperature at each reaction time, $X$ : glucose conversion

The calculations results indicate the same tendency as autoclave experiment but the values are higher than auto- 




Fig. 9 Comparison between estimated glucose decomposition and experimental results

clave experiment results. These differences of reaction should be caused by the fact that the reaction rate equation was derived at temperatures higher than $250^{\circ} \mathrm{C}$, while autoclave experiment was conducted at temperatures lower than $250^{\circ} \mathrm{C}$. However, small modification in the preexponential factor resulted in good agreement between the estimation and experimental results. The calculations using modified equation are given in Fig. 10. The preexponential factor used in this calculation was $1.28 \times$ $10^{7} \mathrm{~s}^{-1}$. Moreover, we applied the equation to the results of different heater output experiments, which is shown in Fig. 11. The calculated values are in good agreement with the experimental ones. Hence it indicates that we can estimate glucose conversion by modified rate equation.

With respect of pretreatment for ethanol fermentation, it is desirable to decompose lignocellulosic material to small saccharides and simultaneously to diminish the decomposition products from monosaccharide. We can estimate whether the reaction condition is suitable or not for pretreatment of fermentation by estimating to what extent lignocellulosic material decompose. To estimate the extent of cellulose hydrolysis in our experiments, we assumed

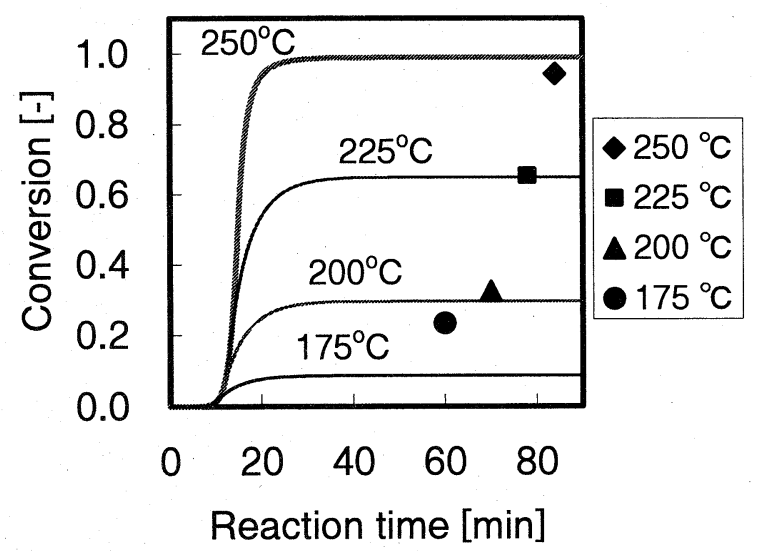

Fig. 10 Comparison between estimation with modified preexponential factor and experimental results

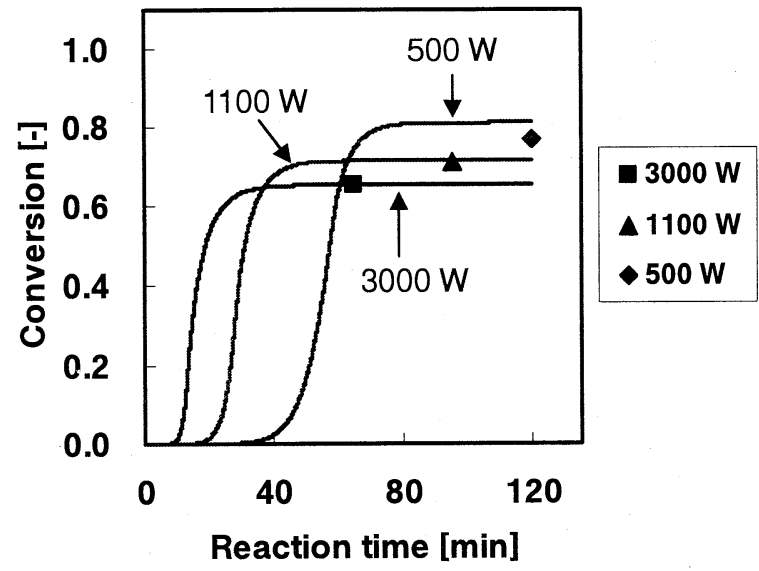

Fig. 11 Estimation of the effect of heater output on glucose decomposition

cellulose hydrolysis process as Fig. 12. Because many kinds of oligomers were detected in cellulose hydrolysis experiment (Fig. 5) cellulose can be assumed to hydrolyze at any ether linkage in its molecule in same way. Therefore we think the reaction scheme in Fig 12 is reasonable. As for the reaction of cellulose decomposition (Fig. 12-A), Sasaki et al. proposed a reaction model in sub- and supercritical water environment ${ }^{6)}$. Though there is difference in pressure between this study and theirs, we employed their rate equation. Furthermore, they investigated cellobiose decomposition in detail ${ }^{6}$, thus we employed this rate equation, too (Fig. 12-C). Many materials and reactions are contained in the reaction process that covers from "intermediate", which are polysaccharides, to cellobiose (Fig. 12-B). For simplicity, we employed activation energy of cellobiose hydrolysis ${ }^{6)}$ for this reaction process, and adjusted preexponential factor to fit the experimental results. Using this simple reaction model, we have calculated glucose yield during cellulose reaction for $225^{\circ} \mathrm{C}$ and $250^{\circ} \mathrm{C}$. The results are shown in Fig. 13, which presents that we succeeded in reproducing the glucose formation tendency of

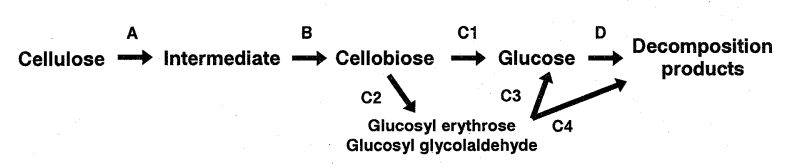

Fig. 12 Reaction scheme for cellulose hydrolysis in hot compressed water
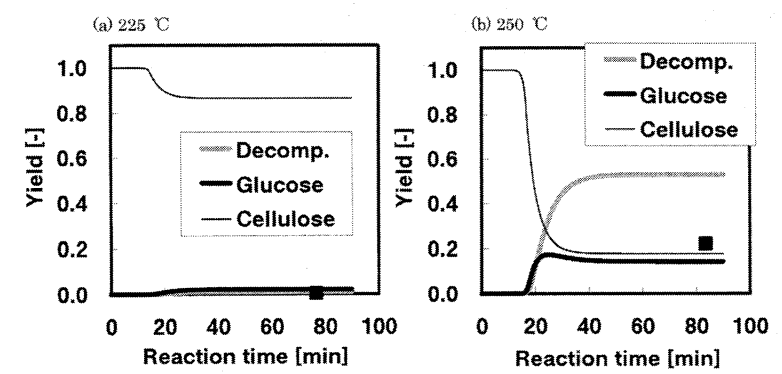

Fig. 13 Estimated glucose production by hydrothermal treatment of cellulose 
temperature dependency.

\section{Conclusions}

We have examined the reaction of cellulose and glucose in hydrothermal environment at temperatures of 150-250 ${ }^{\circ} \mathrm{C}$ using an autoclave-type reactor. We also have conducted glucose decomposition experiments using flow-type reactor and gotten the reaction rate equation. Although the reaction rate equation by flow-type reactor experiments didn't reproduce the experimental results of autoclave-type reactor, modification in preexponential factor resulted in good agreement between estimated and experimental values. Furthermore, we have built a model of cellulose hydrolysis to glucose and glucose decomposition, which reproduces the glucose formation in the cellulose hydrothermal experiments.

\section{Acknowledgment}

This research was carried out financed by the NEDO International Joint Research Grant Program.

\section{References}

1) Sun, Y. and Cheng, J., Bioresource Technol., 83, 1 (2002)

2) Sakaki, T., Shibata, M., Miki, T., Hirosue, H. and Hayashi, N., Energy Fuels, 10, 684 (1996)

3) Sakaki, T., Shibata, M., Miki, T., Hirosue, H. and Hayashi, N., Bioresource Technol., 58, 197 (1996)

4) Sakaki, T., Shibata, M., Miki, T., Yausda, S., Hirosue, H. and Hayashi, N., J. Jpn. Inst. Energy, 77, 241 (1998)

5) Saka, S. and Ueno, T., Cellulose, 6, 177 (1999)

6) Sasaki, M., Adschiri, T. and Arai, K., AIChE J. 50, 192 (2004)

7) Sasaki, M., Furukawa, M., Minami, K., Adschiri, T. and Arai, K., Ind. Eng. Chem. Res., 41, 6642 (2002)

8) Hayashi, N., Fujita, S., Irie, G., Sakaki, T. and Shibata, M., J. Jpn. Inst. Energy, 83, 805 (2004)

9) Negro, M. J., Manzanares, P., Ballesteros, I., Oliva, J. M., Cabanas A. and Ballesteros, M., Applied Biochem. Biotechnol., 105-108, 87 (2003) 